University of Wollongong

Research Online

Faculty of Law, Humanities and the Arts Papers (Archive)

Faculty of Arts, Social Sciences \& Humanities

$1-1-2017$

The sociology of emotions: A meta-reflexive review of a theoretical tradition in flux

Rebecca Olson

University of Queensland

Jordan J. McKenzie

University of Wollongong, jordanmc@uow.edu.au

Roger Patulny

University of Wollongong, rpatulny@uow.edu.au

Follow this and additional works at: https://ro.uow.edu.au/lhapapers

Part of the Arts and Humanities Commons, and the Law Commons

Research Online is the open access institutional repository for the University of Wollongong. For further information contact the UOW Library: research-pubs@uow.edu.au 


\title{
The sociology of emotions: A meta-reflexive review of a theoretical tradition in flux
}

\begin{abstract}
Based in a novel 'meta-reflexive' review of sociology of emotions (SoE) articles, we suggest that there are two primary SoE theoretical traditions that function within geographic silos: the USA is distinctly social psychological, while in the UK and Australia, SoE is more aligned with the humanities. In both traditions, parallel calls are emerging for interdisciplinarity and further engagement with physiological and prepersonal elements of emotion. Based in Archer's and Bourdieu's concepts of reflexivity, we assert the merits of reflexively examining SoE, and then identify key changes in SoE that have emerged across time and geography. Using Kuhn's work on paradigm shifts, we conclude that SoE is entering a stage of growth and change, and raise important questions about the subdiscipline's future direction.

\section{Disciplines}

Arts and Humanities | Law

\section{Publication Details}

Olson, R. E., McKenzie, J. J. \& Patulny, R. (2017). The sociology of emotions: A meta-reflexive review of a theoretical tradition in flux. Journal of Sociology, 53 (4), 800-818.
\end{abstract}


The sociology of emotions: A meta-reflexive review of a theoretical tradition in flux

\begin{abstract}
Based in a novel 'meta-reflexive' review of SoE articles, we suggest that there are two primary SoE theoretical traditions that function within geographic silos: the USA is distinctly social psychological, while in the UK and Australia, SoE is more aligned with the humanities. In both traditions, parallel calls are emerging for interdisciplinarity and further engagement with physiological and pre-personal elements of emotion. Based in Archer's (2012) and Bourdieu's (2003) concepts of reflexivity, we assert the merits of reflexively examining SoE, and then identify key changes in SoE that have emerged across time and geography. Using Kuhn's (1970) work on paradigm shifts, we conclude that SoE is entering a stage of growth and change and raise important questions about the subdiscipline's future direction.
\end{abstract}

Keywords: emotions, reflexivity, sociology, sociology of emotions, systematic review 


\section{Introduction}

The sociology of emotion (SoE) is a relatively new subdiscipline of sociology, emerging in the 1970s (Turner and Stets 2005). ${ }^{1}$ It recognises emotional experience as integral to social life. While the field is often associated with interactionist and dramaturgical sociology (Hochschild 1983a; James 1989), SoE also consists of more macro-theoretical work (Barbalet 1998; Burkitt 1997), quantitative analysis (Author A, Moon et al. 2009) and phenomenological inquiry (Denzin 1983). The identity and direction of the subdiscipline draws from a broad range of disciplines, yet there are unifying methodological premises that arguably provide a sense of commonality among researchers. Risking oversimplification, this can be understood as the view that emotion is intimately tied to key sociological concerns such as identity, structure, inequality, normativity, praxis, community, legitimation, politics, interaction, socialisation, and ethics.

In this article we argue that SoE is currently in a state of flux amid echoing calls for interdisciplinarity. After significant growth in the subdiscipline in the decades following the late 1970s, SoE has become more reflexive, critical and interdisciplinary. Using Bourdieu's (1990) concept of 'field' as a metaphor for the academy and articles as cultural artefacts, we analyse SoE as an area of change and contestation (Swartz 1997). We offer a systematic review of the literature drawing from Archer's (2012) concept 'meta-reflexive,' and suggest that there is not one but many SoE theoretical traditions. We show that while symbolic interactionist theories on emotions are readily used across the globe, SoE 
traditions in the USA are distinctly social psychological, while practices in Europe and Australia are more aligned with debates in the humanities. We present and analyse the parallel calls emerging in these distinct SoE traditions for interdisciplinarity and further engagement with physiological and prepersonal aspects of emotion experienced beyond consciousness. We see the consequent and current period of flux as potentially foreshadowing a paradigmatic shift in the conceptual and methodological bases of the subdiscipline (Kuhn 1970).

In this paper, we establish the merits of reflexively examining SoE and the concepts central to our analysis before outlining the method taken in this review. In the sections that follow, we demonstrate the changes within this subdiscipline that have emerged across time and space. We argue that SoE is undergoing a stage of rapid growth and instability, with mounting pressure for SoE to take on interdisciplinary perspectives. This raises important questions about the future of SoE and its role in public debate.

\section{The reflexive identity of SoE}

In late modernity, it is argued, reliance on traditions is decreasing. Instead, Archer (2012: 1) argues, 'all have to draw upon their ... powers of reflexivity ... to define their course(s) action.' That is, we must embark on internal conversations where we identify our main concerns, the relationships which are most important and then chart a course of action (Archer 2012). Just as individual identities are reflexively mediated, the collective identity of an academic subdiscipline is often constructed and regulated in this way; a subdiscipline is 
able to engage with its identity, and reflect on perceptions of that field held within and by others. In the case of SoE, there is a tendency to see emotion as a neglected theme in mainstream sociological research, such that the subdiscipline is located both within, and in response to, dominant disciplinary debates.

Separate to Archer's (2012) contemporary modernist conceptualisation, Bourdieu (2003: 289) defines reflexivity as applying one's analytic tools to one's practices: knowing 'the world better...as one knows oneself better.' This review of SoE brings both conceptualisations together to 'meta-reflexively' question SoE's theoretical and methodological practices. Using analytic insights fostered through a systematic review, we ask questions about SoE's alliances, methods, aims and future. This involves treating articles and social theories on emotions as cultural artefacts (McCarthy 2002). Cultures shape the way we see, interpret and engage, informing subjectivities and habitus(es) (Bourdieu 1990) or, in the context of the academy, research practices. In this paper, we analyse articles using social theories on emotions as cultural texts to question SoE's reflexive identity. We conceptualise articles engaging with social theories on emotion as cultural artefacts of theoretical traditions used by 'players' (scholars) within the broader university 'field' (Swartz 1997). This is done to facilitate understanding of the 'discordant, conflicting, and incommensurable messages' in the texts (McCarthy 2002: 44) and ask questions about what SoE is, is not, and what it might become. Following Connell (2007), we also ask about the mobility of emotion theories across national borders: is there one SoE, or are there many traditions? To answer these questions, we undertake a 'meta-reflexive' systematic review, acknowledging how this 'distinctive mode of reflexive 
deliberation' (Archer 2012: 32) has become common place in an unprecedentedly self-aware and critical era. Subsequently, we draw on Kuhn's (1970) influential thesis that science moves through revolutions and paradigm changes when faith in a shared theoretical framework wanes, to interpret SoE's past, present and future. Research takes place within specific paradigms that favour particular kinds of analysis and methods of data collection that favour the dominant views of the discipline field. This view describes researchers as embedded within a kind of scientific habitus whereby findings reflect lines of questioning that align with the strengths of specific disciplines. We use Kuhn's (1970) work to conceptualise the progress of subdisciplines as dialectical, transitioning from a shared worldview, to a period of unrest where critiques of this worldview mount, to a period of change that results in a new paradigm, before the (temporary) return of stasis. While these processes can benefit from the challenges posed by interdisciplinary perspectives, blurring discipline boundaries should not be construed as a one-size-fits-all solution to discipline specific criticisms.

\section{Methodology}

Reviews play an important role in any discipline. They 'juxtapose, explain and analyse an assembly of related concepts' asserting how a (sub)discipline 'defines itself and its priorities' (Jutel 2012: 54). Narrative (literature) reviews of SoE have been regular (Kemper 1981; Turner et al. 2006; Stets 2012). Turner and Stets (2005) provide a seminal overview of the theoretical breadth in the subdiscipline, and Greco and Stenner (2008) published a widely read social science reader on emotions, with 55 contributors from Canada, Europe and the 
USA. Most summary publications, however, are largely USA-based and descriptive of new developments within the field rather than methodical, introspective and critical.

Systematic reviews, in contrast, offer a thorough overview of a body of scholarship, and a different vantage point for understanding a field of research. They involve the methodical search for all studies on a subject, the exclusion of studies not meeting predefined standards of methodological rigour and the combination of statistical results to come to cross-study conclusions (Pearson 2004). Meta-synthesis reviews of qualitative studies are valued for their capacity to 'offer a new interpretation of a research question' (Cooke et al. 2012: 1435). They involve the generation of meta-themes, but rarely exclude studies based on 'rigour', as judgements depend on epistemological positioning (Pearson 2004; Dixon-Woods 2011).

Rather than aggregating statistical or thematic findings, as in meta-analyses and meta-syntheses, this 'meta-reflexive' systematic review takes a novel approach: using a systematic and introspective approach to ask questions about the direction, identity and character of SoE; using established search and abstraction techniques we ask 'what is the sociology of emotions?' and 'what is it becoming?'

\section{Method}

A systematic review of SoE in its entirety, including books, articles and reports, would be a task outside the scope of a single article. Thus, a representative approach was taken (Cooke et al. 2012). Four databases were chosen for their 
sociological relevance and international coverage: Informit, Project Muse, Proquest and SocIndex. Boolean operators and truncation symbols (ie 'sociology' AND 'emotion*') were employed to locate journal articles with subject terms relevant to SoE. The multidisciplinary journal Emotion Review was also hand searched. Searches were limited to journal articles appearing in English between 1978, the year Kemper (1978) proposed the subdiscipline' ${ }^{1}$, and June 2015.

Not every publication that references emotion qualified. The defining characteristic of included articles was the use of emotion to make sense of social life. Thus, only articles that applied, developed or critiqued social theory(ies) on feelings and/or emotion were included. ${ }^{2}$ Articles that primarily reported empirical findings without reference to SoE theories were excluded. Titles and abstracts were assessed on such criteria. Full texts were reviewed and reflective notes taken if the study clearly met the inclusion criteria, or if there was any question about eligibility. Using a purpose built abstraction table created in Microsoft Excel (2011), the following was also extracted from each article: (1) author details including discipline, institution, and location; (2) article details including title, year of publication, journal title, journal discipline and journal location (based on affiliation with an association or a review of the current editorial board); (3) article type (theoretical, empirical and/or review) and, where appropriate, method; and (4) article contribution including the theory(ies) used and the overarching argument. Information not readily available from journal articles, such as authors' current discipline, was determined through an online search. Abstracting this data was done to foster an examination of SoE's current state, how it is conceptualised across national 
boundaries and time, allowing for a critical and meta-reflexive analysis of what it is and where it is going.

\section{Findings}

Findings are discussed here in light of the relevant literature. Because of space limitations, a representative approach is taken; illustrative rather than exhaustive citations are provided. Drawing on Appadurai (1996), findings are organised into four reflexive 'scapes' - descriptive, global, historical and critical that raise questions about the subdiscipline's future. As such, this vantage point for analysis should not be viewed as fixed and objective, but 'perspecitval' and subject to change (Appadurai 1996). We describe SoE's present advancement and global reach before examining its history, so that an introspective and critical exploration of SoE's past and future can be established with reference to its present status.

\section{A descriptive view: SoE's advancement}

No longer in its infancy, SoE has developed with increasing momentum over the past three decades. Illustrating SoE's expansion, the systematic search conducted for this review resulted in 1,790 hits, with $228 \operatorname{articles}^{3}$ meeting the inclusion criteria (see figure 1).

[Figure 1 here]

The majority of included articles were published in the last two decades, with a substantial increase in output since 2003. Articles were split between those 
focused on developing or critiquing theory(ies) (90) and empirical articles applying and extending SoE theories (98). The remaining (40) articles were commentaries and reviews of the subdiscipline as a whole (Thoits, 1989; von Scheve and von Luede 2005; Turner 2009), a specific SoE theory (Smith-Lovin 1987), or application of SoE theories to a particular topic or setting (Flam 2002). Empirical studies integrated (19 articles used mixed methods) a range of methods (see figure 2), favouring interviews and surveys.

[Figure 2 here]

Most included articles were single-authored (145), written by scholars working in sociology departments and publishing in sociology journals (see table 1). While this indicates a strong interest in social theories on emotions within sociology, there was evidence of interest in the explanatory appeal of these theories in neighbouring disciplines; 23 authors were based in faculties of Business and Human Resource Management.

[Table 1 here]

\section{A global view: A plurality of SoE traditions}

The growth of the subdiscipline has been at once united and divergent across the world. Perhaps reflecting different research traditions in the UK and USA, crossAtlantic publishing was limited ${ }^{4}$. A majority of articles were written by authors within a single country, with the USA (116), the UK (40), Australia (32) and Germany (8) leading the tally. Only 10 articles (see Harding and Pribram 2004; 
Moon et al. 2009; Bellocchi et al. 2014; Roach Anleu et al. 2015) were the result of cross-country collaboration (Australia-USA (4); Australia-Sweden (1); UK-USA (1); USA-Canada-Germany (3); USA-South Korea (1)). Dots in figure 3 represent authors' locations; lines represent collaborations.

[Figure 3 here]

The journal with the highest number of included articles (other than Emotion Review (37) which was hand searched) was the UK journal Sociology (16), followed by USA-based journals American Journal of Sociology (14), Social Forces (8), Sociological Spectrum (5) and Social Psychology Quarterly (5), and the Australian Journal of Sociology (5). International journals The Sociological Review (7) and Studies in Symbolic Interaction (6) also ranked highly. Of the 32 articles in the 4 USA-based journals above, only two co-authors were from outside of the USA. Contributors to articles published in the Journal of Sociology were similarly Australian-based, bar one USA-based co-author. The British journal Sociology showed more international exchange, with included articles submitted by authors from the UK (10), Australia (3), Ireland (2) and Israel (1).

While interactionist and classic sociological theories share wide appeal, findings indicate that in addition to national publishing silos, there are preferences for certain theories across and within national borders (see figure 4). Internationally, engagement with interactionist theories - including dramaturgical approaches such as Hochschild's (1983a) - predominated. Over 60 articles, published by authors across the globe, employed Hochschild's 
(1983a) concepts of emotion management and feeling rules (James 1989; Fine and Fields 2008; Cohen 2010), often in combination with other theories (Wouters 1992; Martin 2000; Taylor 2010). Collins' theory of Interaction Ritual Chains (2004) was used in 22 articles (Boyns and Appelrouth 2011; Parker and Hackett 2012; Dolan and Connolly 2014) by primarily USA-based authors. Macro-sociological approaches to understanding the stratified power dimensions of emotion, using theories by Kemper (1978), Barbalet (1998) and others, were used in over 30 studies by mainly USA-based authors (Ridgeway and Johnson 1990; Heaney 2011; Ray 2014). Engagement with classic interactionist theorists such as Mead (2000) and Cooley (1998) was similarly USA-dominated (Denzin 1983; Bandelj 2009; Qi 2011).

Another international theoretical trend within SoE included re-visiting classic sociological texts by Durkheim, Simmel, Weber and Marx for their emotional content (Shilling 1997; Barbalet 2006; Weyher 2012). Bourdieu's concepts, such as habitus (Scheer 2012; Dolan and Connolly 2014) and practice theory (Lutz and White 1986; Johnson 2010), were also popular with authors across the USA, Europe and Australia. An extension of Bourdieu's concepts, 'emotional capital,' however, was used exclusively in articles focusing on education (Reay 2000; Forbes and Weiner 2008; Nixon 2011) by authors outside of the USA.

The appeal of other theories was contained within national borders. The use of three theories was nearly exclusive to the USA: Affect Control Theory (Lively and Heise 2004; Heise and Lerner 2006; Rogers et al. 2013); Identity Theory (Robinson et al. 2004; Stets and Carter 2012); and General Strain Theory, which 
was employed almost exclusively in articles published in criminology journals (Moon et al. 2009; Slocum et al. 2012). Theories on affect, civilisation and reflexivity in late modernity did not appear as popular in the USA. Articles engaging with theories related to the affective turn in cultural studies (see Massumi 2002; Hardt and Negri 2004) were primarily authored by Australians (Author B; Labanyi 2010; Faircloth 2011; Lupton 2013). Elias's theories on civilisation and emotion were used chiefly by authors in Europe (Wouters 1995; Burkitt 1997; Berezin 2002). Articles using theories of reflexivity in late modernity were written mainly by Australian and European authors (Deslandes and King 2006; Burkitt 2012; Holmes 2015).

[Figure 4 here]

This depicts SoE as a subdiscipline of many theoretical traditions: united in the use of interactionist and classic sociological theories, but working within national silos. In the next section, divisions across theories and historical disciplines are discussed.

\section{An historical view: Conquests, rediscoveries and internal divisions}

Traditionally, 'inner experiences' such as emotions, had been viewed as subjects outside of sociology's repertoire (Junge 2008: 43). Following its introduction in the late 1970s, sociologists engaged in an interdisciplinary scrum with psychology over the contested terrain of emotions. This 'border skirmish' (Williams and Bendelow 1996: 145) between psychology and sociology seems to have defined SoE in the 1980s and 1990s. Sociology was seen to be taking 
territory away from psychology. Stearns (1989: 594 our emphasis) used 'conquest' language to describe sociology as having 'carved out a lead in examining the social functions and contexts for emotion.' Fine and Fields (2008: 142 our emphasis) described sociology's entrance onto the emotions scene in the 1970 s as 'when sociologists first began to colonize emotion.' During this time, sociology metaphorically claimed emotions, pushing psychology to share the academic field and living up to Urry's (2005) description of the discipline as parasitic.

Simultaneously, sociologists worked to re-claim emotion as part of their own disciplinary history. Before the 1970s, as Weyher (2012: 341) explains, emotions were 'largely excluded from the sociological lexicon...the very reading of classic texts [had] been historically biased against the seeing of emotions' - perhaps reflecting sociology's origins in post-enlightenment and its concern with understanding the industrial revolution. Since the 1970s, as this review illustrates, sociologists have prioritised re-reading classical sociological texts by Simmel, Durkheim, Weber, Elias and others to rediscover the emotional aspects of theories that were previously inaccessible or overlooked (Shilling 1997; Barbalet 2006; Hopkins et al. 2009). This suggests the importance of social theories on emotions within and beyond the habitus, subjectivity and dispositions of the discipline (and those disciplined by it).

If SoE in the 1980s to 1990s was characterised by competition for emotional terrain, SoE of the 1990s to 2000s could be described as a period of growth, application and internal debate. During this phase, the application of social 
theories on emotions began to grow in diverse fields. Hochschild's concept of emotional labour in particular took firm root in the organisational management literature (Morris and Feldman 1996; Glomb and Tews 2004; Hampson and Junor 2010). Social theories on emotion, ranging from Collins (Milne and Otieno 2007) to Bourdieu (Forbes and Weiner 2008), became staples of the education literature.

Yet SoE grew as a fractured subdiscipline during this time. While Turner (2010) divides emotions theories along micro and macro scopes, others highlight distinctions between interactionist theories, which value emotions as consciously acknowledged and culturally relative (Harding and Pribram 2004), and theories that depict emotions as both conscious and unconscious universal phenomena with structural properties (von Scheve and von Luede 2005; Wang and Roberts 2006). When dramaturgical approaches like Hochschild's (1983a) are categorised as a branch of interactionism, the former clearly enjoys a position of dominance within SoE, with a majority of articles employing interactionist social theories. Figure 4 also shows that there are numerous articles using structural theories. Several important critiques of interactionist perspectives have recently arisen. Barbalet, for example, has emphasised the importance of biology to emotion. 'Emotions are always physical, involving the hormonal, muscular, and neural systems, and they are always socialstructural....[and] cultural' (Barbalet 2006: 52). Many, from social psychology (Turner 2009) to cultural studies (Labanyi 2010), assert a need to re-evaluate emotions as biological, pre-personal and culturally and consciously mediated. 
While there are calls emerging from the USA and Europe for SoE to engage with neurological, physiological and evolutionary aspects (Berezin 2002; von Scheve and von Luede 2005; Turner 2009), there are also calls to engage with affect - a concept with roots in Tomkins' early psychological theories (Hemmings 2005) emerging from Australia, the UK and, to a lesser extent, the USA (Labanyi 2010; Faircloth 2011; Lupton 2013). There is increasing interest amongst many sociologists in pre-conscious and non-verbal aspects of embodied feeling, and in concepts that include the embodied relationality between people and things, involving sounds, pheromones and other forms of exchange (Faircloth 2011; Seyfert 2012; Hynes 2013). This interest aligns with the affective turn, and also channels literature from the sociology of the body that critiques the undue emphasis given to socialisation or rational choice in explaining action (Shilling 2007).

Thus, it seems the disciplinary boundary work (Witz 1992) and the exclusionary and usurpationary strategies that characterised SoE in the 1980s and 1990s, have been replaced with repeated calls for interdisciplinarity.

\section{A critical view of Interdisciplinarity: Liberating or limiting?}

The shift from conquest-oriented boundary work to interdisciplinary collaboration begs the questions: (1) why now?, (2) what form will this proposed interdisciplinarity take?, and (3) how will this interdisciplinarity shape our collective subjectivity and praxis as a discipline? 
Why now? Why are alignments with neuroscience, psychology and biology now more 'palatable' (Clarke 2006: 1154) to sociologists of emotion across theoretical traditions? Several answers seem possible. Perhaps the subdiscipline is now well enough established to withstand multidisciplinary (Williams and Bendelow 1996; Berezin 2002) or even interdisciplinary collaboration. Perhaps past debates within SoE that were once acrimonious (Hochschild 1983b; Kemper 1981; Kemper 1983) have 'ceased now in favour of a more mature and less contentious debate' (von Scheve and von Luede 2005: 303).

Alternatively, calls for interdisciplinarity may reflect wider trends in academia. Undergirded by logics of innovation, accountability and governance (O'Reilly 2009; Garforth and Kerr 2011), academics are 'currently subject to...relentless encouragement to be interdisciplinary' (Cooper 2013: 79). Interdisciplinary research is heralded as less reductionist and more 'democratic' (Cooper 2013: 78), commanding 'a high priority for...research funding' (Garforth and Kerr 2011: 657) and reflecting wider neoliberal discourses.

A third explanation might situate current calls for interdisciplinarity in SoE as based in a long history of 'fragmentation' and 'hybridization' within sociology (Garforth and Kerr 2011: 659). Sociology, Urry (2005) argues, is an un-centred discipline that has historically responded to and incorporated varied intellectual and social movements. Thus, current calls for interdisciplinarity in SoE might be understood as yet another change in a social science with 'fuzzy boundaries' and 'ever-changing methods, theories and research fields' (Garforth and Kerr 2011: 659). 
A fourth possibility is that SoE's maturity, with its own methods and research outputs - particularly following the popularity of Hochschild's (1983a) work has attracted interest from other disciplines wanting to more fully explore the social dimensions of familiar emotions (in psychology) or the emotional dimensions of social situations (in law, education, history, etc.).

Regardless of the impetus behind the calls for interdisciplinarity, we argue that should calls for further engagement with neuroscience, biology and psychology be met $^{5}$ - this will have real consequences. In line with Kuhn (1970), these resounding critiques of the core theories that make up SoE can be viewed as a 'crisis' point with the potential to usher in a new 'worldview' or paradigmatic era for the subdiscipline - an era with substantially different cultures, methods and practices.

Fine and Fields (2008) argue that cultures shape emotions and emotions shape and alter cultures. Clearly, disciplinary traditions, practices and culture have affected sociologists' abilities to perceive and appreciate emotions in subjects and theories, necessitating the re-reading of classical sociological texts for their emotional dimensions. Interdisciplinarity, involving the blurring of biological, psychological and sociological lenses that accommodate for the social, physiological and pre-conscious, could similarly have an effect on our academic subjectivities. 
If our theories change to address our neglect of biology and the unconscious, our methods will also certainly need to change. ${ }^{6}$ Interviews and surveys are less adept at capturing the unconscious, physiological and intersubjective (Author C; Prosser et al. 2013). ${ }^{7}$ One of our main concerns will need to be how to measure what eludes consciousness and language (Holmes 2004). If we conceptualise sympathy as an affect felt along with others (Labanyi 2010), then we will need to conceptualise feelings as co-productions between and across researchers and participants - not as something done to or extracted from participants (Prosser 2015). Scholars have begun to suggest ways in which qualitative research and textual analysis might be re-imagined to access affect and intersubjective emotion (Author D; Poynton and Lee 2011; Wetherall 2013). Further innovation and reflection is needed to capture the elements of affect that are beyond cognition; to overcome the challenge of avoiding the imposition of categories, order and language on pre-discursive phenomena; and fully appreciate the challenge that affect poses to traditional ontological assumptions in sociology that frame reality within the confines of consciousness (see Packer 2011).

Finally, the way we conceptualise emotions may substantially affect how we practice sociology. Cooper (2013) argues that when we change our theoretical and epistemological frameworks, we also change our study outcomes. Theoretical traditions impose certain conditions on the conclusions that can be made because of the assumptions underpinning these traditions (especially regarding neutrality). Theoretical shifts can also potentially alter our social worlds. Montgomery's (2008) empirical findings related to public (emotional) health messages following the beginning of the US-Iraq war serve as an example. 
The Bush Administration, with The American Psychological Association, advised parents to turn off the news and manage their emotional responses to viewing video footage of the war to reduce its traumatic impact on children. Montgomery (2008) argues that framing emotions as potentially harmful had the consequence of propagating political submission.

Thus, theoretical and epistemological emotion frameworks matter. An overly psychological or therapeutic 'emotions as damaging' discourse can undermine social change, encouraging emotion management and passivity over political action. ${ }^{8}$ This is, perhaps, most concerning given sociology's commitment to 'mak[ing] a difference in the world' - to engagement with public debate and emancipation (Bauman 2008: 237). The main challenge in responding to calls for interdisciplinarity in SoE is negotiating a path around the individualising, pathologising, normalising and regulating potential perpetuated in many models of emotion that incorporate 'psychical and neurological functioning' (Blackman et al. 2008: 10).

\section{Conclusion}

This article's contribution is twofold: a novel meta-reflexive approach to the qualitative systematic review and a critical analysis of SoEs' fractured history and interdisciplinary future. Combining reflexive insight with methodical rigour, this article demonstrates the merits of a revised form of critical review: a metareflexive systematic review. As illustrated above, reflexively analysing SoE's praxes, traditions and subjectivities can be a theoretically productive exercise, 
highlighting taken-for-granted elements of the knowledge production process (Author E; Gray 2008; Carroll 2012).

In treating articles as cultural texts, this paper also illustrates that SoE is made up of numerous traditions with cross-national fractures. Possibly reflecting sociology's long history of fragmentation (Garforth and Kerr 2011), epistemological, methodological and curriculum differences across national borders divide SoE traditions (Babones 2013). Though all SoE theories share a foundation in interactionist theories, the SoE subdiscipline in the USA is distinct in its institutional affiliation with social psychology; by contrast in Australia, for example, social psychology tends to be located within psychology departments and disciplines, and does not share as close of a connection with sociology (Feather 2005). The SoE subdiscipline outside of the USA is more engaged with approaches that consider emotions in late modernity or the affective derivations of emotions.

The meta-reflexive examination of SoE articles over time offered a reading of SoE's history. After a formative period of claiming emotions as an appropriate subject for social inquiry and part of our discipline's history, as well as periods of surge and calm in internal debates, scholars engaging with diverging SoE theoretical traditions - from social psychology to affect - are now converging to insist that pre-conscious and physiological aspects of emotion be taken into account. 
These demands reflect the shortcomings of interactionist approaches to incorporating biological aspects of emotion. Calls are now being made for collaboration in emotion research across sociology, biology, psychology and cultural studies. Marking a new chapter in SoE's paradigmatic evolution (Kuhn 1970), an interdisciplinary future seems likely and reasonable given the differing expertise available. But, the new interdisciplinary 'worldview' in SoE being ushered in, could have real, subjective and methodological impacts affecting our primary concern as sociologists: improving our social world(s). We urge emotions sociologists to keep sight during this transition of the specialised contribution that SoE is able to make.

It is time for emotions sociologists to ask if this interdisciplinary shift (and its associated methodological challenges) is cause for excitement, fear or something else entirely. How will epistemologies be stretched or replaced? How will this open or close certain lines of thinking or seeing? Rather than a conservative call for boundary protection, we suggest that there will undoubtedly be benefits to sharing theories and methods across disciplinary and national divides. The physiological and pre-conscious limitations of current sociological theories on emotions, clearly, cannot be ignored. However, there is a need to proceed with reflection and consideration. As Blackman et al. (2008: 10) urge, "There is far more work to be done...in linking the current recourse to affect...with models of psychical or neurological functioning that do not bring in psychological individualism through the back door.' 
As scholars employing and refining SoE theories embark on this new chapter, praxis should be prioritised. Ongoing reflection on action should help to ensure that SoE scholars do not lose sight of sociology's role within the academic field, and keep goals of prediction and rigour from overshadowing the equally important goals of critical commentary, emancipation, and phronesis - opening our imaginations to new forms of 'being' and practice (Packer 2011: 14).

\section{Footnotes}

${ }^{1}$ A Google Ngram search for 'sociology of emotions' shows no evidence of the term being adopted before the late 1970s, with the most significant growth in use of the term between 1980 and 2000 .

${ }^{2}$ Only articles using affect to conceptualise the social, pre-personal precursors to emotion were deemed relevant.

${ }^{3}$ Most articles not meeting the inclusion criteria were excluded because emotions were treated clinically as intervention outcomes. ${ }^{4}$ There are important developments in SoE emerging in South America (eg Scribano's work), but most citations come from northern geographic areas.

5 Or continue. O’Reilly (2009: 221) argues that SoE has already 'embraced links to biology and psychology'. Several included articles show emerging interdisciplinarity (Smith-Lovin and Winkielman 2010).

${ }^{6}$ Identities may also change. O’Reilly (2009) warns that new disciplines crafted in the wake of interdisciplinary collaboration can be temporary and disruptive to an ongoing academic identity and employability. 
${ }^{7}$ Surveys of emotion can, however, identify associations between experiences and management of emotion, and various predictors (gender, age) and outcomes (health, crime) that may not be understood consciously by singular respondents. ${ }^{8}$ Critical psychology poses an important exception.

\section{References}

Author A

Author B

Author C

Author D

Author E

Appadurai, A. (1996) Modernity at Large: Cultural Dimensions of Globalization. Minneapolis: University of Minnesota Press.

Archer, M. (2012) The Reflexive Imperative in Late Modernity. Cambridge: Cambridge University Press.

Babones, S. (2013) 'Sociology in Australia: A Discipline Findings its Way in the World', Footnotes, 41(4): 5.

Bandelj, N. (2009) 'Emotions in Economic Action and Interaction', Theory and Society, 38(4): 347-366.

Barbalet, J. (1998) Emotion, Social Theory, and Social Structure: A Macrosociological Approach. Melbourne: Cambridge University Press.

Barbalet, J. (2006) 'Emotion', Contexts: Understanding People in Their Social Worlds, 5(2): 51-53.

Barry, A., Born, G. and G. Weszkalnys (2008) 'Logics of Interdisciplinarity', Economy and Society, 37(1): 20-49. 
Bauman, Z. (2008) 'Bauman on Bauman - pro domo sua', pp. 231-240 in: M. Jacobsen and P. Poder (eds.) The Sociology of Zygmunt Bauman: Challenges and Critiques. Hampshire, England: Ashgate.

Bellocchi, A., Ritchie, S., Tobin, K., King, D., Sanhu, M. and S. Henderson (2014) 'Emotional Climate and High Quality Learning Experiences in Science Teacher Education', Journal of Research in Science Teaching, 51: 13011325.

Berezin, M. (2002) 'Secure States: Towards a Political Sociology of Emotion', Sociological Review Monograph, 50(1): 33-52.

Blackman, L., Cromby, J., Hook, D., Papadopoulos, D. and V. Walkerdine (2008) 'Editorial: Creating Subjectivities', Subjectivity, 22: 1-27.

Bloch, C. (2002) 'Managing the Emotions of Competition and Recognition in Academia', Sociological Review Monograph, 50(1): 113-131.

Bourdieu, P. (1990) The Logic of Practice. Stanford: Stanford University Press. Bourdieu, P. (2003) 'Participant Observation: The Huxley Medical Lecture', Journal of the Royal Anthropological Institute, 9(2): 281-294.

Boyns, D. and A. Appelrouth (2011) 'Studies in the Suspension of the "Flow" of Social Life', Sociological Spectrum, 31(2): 193-223.

Burkitt, I. (1997) 'Social Relationships and Emotions', Sociology, 31(1): 37-55. Burkitt, I. (2012) ‘Emotional Reflexivity: Feeling, Emotion and Imagination in Reflexive Dialogues', Sociology, 46(2): 458-472.

Carroll, K. (2012) 'Infertile? The Emotional Labour of Sensitive and Feminist Research Methodologies', Qualitative Research, 13(5): 546-561.

Clarke, S. (2006) ‘Theory and Practice: Psychoanalytic Sociology as Psycho-Social Studies', Sociology, 40(6): 1153-1169. 
Cohen, R. (2010) 'When it Pays to be Friendly: Employment Relationships and Emotional Labour in Hairstyling', The Sociological Review, 58(2): 197-218.

Collins, R. (2004) Interaction Ritual Chains. Princeton: Princeton University Press.

Connell, R. (2007) Southern Theory: A Global Dynamics of Knowledge in Social Science. Crows Nest, NSW: Allen \& Unwin.

Cooke, A., Smith, D. and A. Booth (2012) 'Beyond PICO: The SPIDER Tool for Qualitative Evidence Synthesis', Qualitative Health Research, 22(10): $1435-1443$.

Cooley, C.H. (1998) On Self and Social Organization. Chicago: University of Chicago Press.

Cooper, G. (2013) 'A Disciplinary Matter: Critical Sociology, Academic Governance and Interdisciplinarity', Sociology, 47(1): 74-89.

Denzin, N.K. (1983) 'A Note on Emotionality, Self, and Interaction', American Journal of Sociology, 89(2): 402-409.

Deslandes, A. and D. King (2006) 'Autonomous Activism and the Global Justice Movement: Aesthetic Reflexivity in Practice', Journal of Sociology, 42(3): 310-327.

Dixon-Woods, M. (2011) 'Systematic Reviews and Qualitative Methods', pp. 331346 in D. Silverman (ed.) Qualitative Research: Issues of Theory, Method and Practice. Singapore: Sage.

Dolan, P. and J. Connolly (2014) 'Emotions, Violence and Social Belonging: An Eliasian Analysis of Sports Spectatorship'. Sociology, 48(2): 284-299.

Faircloth, C. (2011) 'It Feels Right in my Heart': Affective Accountability in Narratives of Attachment', The Sociological Review, 59(2): 283-302. 
Farrar, M. (2013) 'How Can We Meet 'The Demands of the Day'? Producing an Affective, Reflexive, Interpretive, Public Sociology of 'Race", Ethnic and Race Studies, 36(9): 1446-1464.

Feather, N.T (2005) 'Social Psychology in Australia: Past and Present'. International Journal of Psychology, 40(4): 263-276.

Fine, G. and C. Fields (2008) 'Culture and Microsociology: The Anthill and the Veldt', The Annals of the American Academy of Political and Social Science 619: $130-148$.

Flam, H. (2002) 'Corporate Emotions and Emotions in Corporations', Sociological Review Monograph, 50(1): 90-112.

Forbes, J. and G. Weiner (2008) 'Under-Stated Powerhouses: Scottish Independent Schools, Their Characteristics and Their Capitals', Discourse: Studies in the Cultural Politics of Education, 29(4): 509-525.

Garforth, L. and A. Kerr (2011) 'Interdisciplinarity and the Social Sciences: Capital, Institutions and Autonomy', The British Journal of Sociology, 62(4): 657-676.

Glomb, T. and M. Tews (2004) 'Emotional Labor: A Conceptualization and Scale Development', Journal of Vocational Behavior, 64: 1-23.

Gray, B. (2008) 'Putting Emotion and Reflexivity to work in Researching Migration', Sociology, 42(5): 935-952.

Greco, M. and P. Stenne (2008) Emotions: A Social Science Reader. London: Routledge.

Hampson, I. and A. Junor (2010) 'Putting the Process Back in: Rethinking Service Sector Skill', Work, Employment \& Society, 24(3): 526-545. 
Harding, J. and D. Pribram (2004) ‘Losing Our Cool? Following Williams and Grossbery on Emotions', Cultural Studies, 18(6): 863-883.

Hardt, M. and A. Negri (2004) Multitude: War and Democracy in the Age of Empire. New York: Penguin Books.

Heaney, J. (2011) 'Emotions and Power: Reconciling Conceptual Twins', Journal of Political Power, 4(2): 259-277.

Heise, D. and S. Lerner (2006) 'Affect Control in International Interactions', Social Forces, 85(2): 993-1010.

Hemmings, C. (2005) 'Invoking Affect', Cultural Studies, 19(5): 548-567.

Hochschild, A. (1983a) The Managed Heart. Berkeley, CA: University of California Press.

Hochschild, A. (1983b) 'Comment on Kemper's "Social Constructionist and Positivist Approaches to the Sociology of Emotions"', American Journal of Sociology, 89(2): 432-434.

Holmes, M. (2004) 'Importance of Being Angry: Anger in Political Life', European Journal of Social Theory, 7(2): 123-132.

Holmes, M. (2015). 'Researching Emotional Reflexivity', Emotion Review, 7(1): 61-66.

Holmwood, J. (2010) ‘Sociology’s Misfortune: Disciplines, Interdisciplinarity and the Impact of Audit Culture', British Journal of Sociology, 61(4): 639-658.

Hopkins, D., Kleres, J,. Flam, H. and H. Kuzmics (eds.) (2009) Theorizing Emotions: Sociological Explorations and Applications. Frankfurt: Campus Verlag. Hynes, M. (2013) 'Reconceptualizing Resistance: Sociology and the Affective Dimension of Resistance', British Journal of Sociology, 64(4): 559-577. 
James, N. (1989) 'Emotional Labour: Skill and Work in the Social Regulation of Feelings', The Sociological Review, 37: 15-42.

Johnson, J. (2010) ‘Using Gender: The Personal, Interpersonal, and Emotional Strategies of Domestic Labor', Sociological Spectrum, 30(6): 695-724.

Junge, M. (2008) 'Bauman on Ambivalence - Fully Acknowledging the Ambiguity of Ambivalence', pp. 41-56 in: M. Jacobsen and P. Poder (eds.) The Sociology of Zygmunt Bauman - Challenges and Critique. Hampshire, England: Ashgate.

Jutel, A. (2012) 'Commentary: Method or Madness? The Dominance of the Systematic Review in Nursing Scholarship', Aporia: The Nursing Journal, $4(4): 52-57$.

Kemper, T. (1978) 'Toward a Sociology of Emotions: Some Problems and Some Solutions', American Sociologist, 13(1): 30-41.

Kemper, T. (1981) 'Social Constructionist and Positivist Approaches to the Sociology of Emotions', American Journal of Sociology, 87(2): 336-362.

Kemper, T. (1983) 'Reply to Hochschild and Hunsaker', American Journal of Sociology, 89(2): 440-443.

Kuhn, T. (1970) The Structure of Scientific Revolutions. Chicago: University of Chicago Press.

Labanyi, J. (2010) 'Doing Things: Emotion, Affect, and Materiality', Journal of Spanish Cultural Studies, 11(3/4): 223-233.

Lively, K. and D. Heise (2004) 'Sociological Realms of Emotional Experience', American Journal of Sociology, 109(5): 1109-1136.

Lupton, D. (2013) 'Risk and Emotion: Towards an Alternative Theoretical Perspective', Health, Risk \& Society, 15(8): 634-647. 
Lutz, C. and G. White (1986) 'The Anthropology of Emotions', Annual Review of Anthropology, 15: 405-436.

Martin, D. (2000) ‘Organizational Approaches to Shame: Avowal, Management, and Contestation', The Sociological Quarterly, 41(1): 125-150.

Massumi, B. (2002) Parables for the Virtual: Movement, Affect, Sensation. London: Duke University Press.

McCarthy, E. (2002) 'The Emotions: Sense of the Modern self', Österreichische Zeitschrift für Soziologie, 27(2): 30-49.

Mead, G. H. (2000) 'Mind, Self and Society', pp. 160-178 in: J. Farganis (ed.) Readings in Social Theory: The Classic Tradition to Post-Modernism. Boston: McGraw-Hill.

Milne, C. and T. Otieno (2007) 'Understanding Engagement: Science Demonstrations and Emotional Energy', Science Education, 91(4): 523553.

Montgomery, A. (2008) 'Therapeutic vs. Political Frames: The Influence of "Witnessing" the U.S.-Iraq War on Family "Agitation"', Sociological Perspectives, 51(3): 605-627.

Moon, B., Morash, M., McCluskey, C. and H. Hwang (2009) 'A Comprehensive Test of General Strain Theory: Key Strains, Situational- and Trait-Based Negative Emotions, Conditioning Factors, and Delinquency', Journal of Research in Crime \& Delinquency, 46(2): 182-212.

Morris, A. and D. Feldman (1996) 'The Dimensions, Antecedents, and Consequences of Emotional Labor', Academy of Management Review, 21(4): 996-1010. 
Nixon, C. (2011) 'Working-class Lesbian Parents' Emotional Engagement with Their Children's Education: Intersections of Class and Sexuality', Sexualities, 14(1): 79-99.

O'Reilly, K. (2009) ‘For Interdisciplinarity and a Disciplined, Professional Sociology', Innovation: The European Journal of Social Science Research, 22(2): 219-232.

Packer, M. (2011) The Science of Qualitative Research. Cambridge: Cambridge University Press.

Parker, J. and E. Hackett (2012). 'Hot Spots and Hot Moments in Scientific Collaborations and Social Movements', American Sociological Review, 77(1): 21-44.

Pearson, A. (2004) 'Balancing the Evidence: Incorporating the Synthesis of Qualitative Data into Systematic Reviews', JBI Reports, 2: 45-64.

Poynton, C. and A. Lee (2011) 'Affect-ing Discourse: Towards an Embodied Discourse Analytics', Social Semiotics, 21(5): 633-644.

Prosser, B., Tuckey, M. and S. Wendt (2013) 'Affect and the Lifeworld: Conceptualising Surviving and Thriving in the Human Service Professions', Health Sociology Review, 22(3): 318-327.

Prosser, B. (2015) 'Knowledge of the Heart: Ethical Implications of Sociological Research with Emotion', Emotion Review, 7(2): 175-180.

Qi, X. (2011) 'Face: A Chinese Concept in a Global Sociology', Journal of Sociology, 47(3): 279-295.

Ray, L. (2014) 'Shame and the City - 'Looting', Emotions and Social Structure', The Sociological Review, 62: 117-136. 
Reay, D. (2000) 'A Useful Extension of Bourdieu's Conceptual Framework? Emotional Capital as a way of Understanding Mothers' Involvement in their Children's Education?', The Sociological Review, 48(4): 568-585.

Ridgeway, C. and C. Johnson (1990) 'What is the Relationship Between Socioemotional Behaviour and Status in Task Groups?', American Journal of Sociology, 95(5): 1189-1212.

Roach Anleu, S., Bergman Blix, S. and K. Mack (2015) ‘Researching Emotion in Courts and the Judiciary: A Tale of Two Projects', Emotion Review, 7: 145150.

Robinson, D., Rogalin, C. and L. Smith-Lovin (2004) 'Physiological Measures of Theoretical Concepts: Some Ideas for Linking Deflection and Emotion to Physical Responses During Interaction', Advances in Group Processes, 21: $77-115$.

Rogers, K., Schröder, T. and W. Scholl (2013) 'The Affective Structure of Stereotype Content: Behavior and Emotion in Intergroup Context', Social Psychology Quarterly, 76(2): 125-150.

Scheer, M. (2012) 'Are Emotions a Kind of Practice (and is That What Makes Them Have a History)? A Bourdieuian Approach to Understanding Emotion', History and Theory, 51(2): 193-220.

Seyfert, R. (2012) 'Beyond Personal Feelings and Collective Emotion: Toward a Theory of Social Affect', Theory, Culture \& Society, 29(6): 27-46. Shilling, C. (1997) 'Emotions, Embodiment and the Sensation of Society', The Sociological Review, 45(2): 195-219.

Shilling, C. (2007) 'Sociology and the Body: Classical Traditions and New Agendas, The Sociological Review, 55(1): 1-18. 
Slocum, L., Rengifo, A. and K. Carbone-Lopez (2012) 'Specifying the StrainViolence Link: The Role of Emotions in Women's Descriptions of Violent Incidents', Victims and Offenders, 7(1): 1-29.

Smith-Lovin, L. (1987) 'Affect Control Theory: An assessment', Journal of Mathematical Sociology, 13(1/2): 171-192.

Smith-Lovin, L. and P. Winkielman (2010) 'The Social Psychologies of Emotion: A Bridge that is Not Too Far', Social Psychology Quarterly, 73(4): 327-332. Stearns, P. (1989) 'Social History Update: Sociology of Emotion', Journal of Social History, 22(3): 592-599.

Stets, J. and M. Carter (2012) 'A Theory of the Self for the Sociology of Morality', American Sociological Review, 77(1): 120-140.

Stets, J. (2012) 'Current Emotion Research in Sociology: Advances in the Discipline', Emotion Review, 4: 326-334.

Swartz, D. (1997) Culture and Power: The Sociology of Pierre Bourdieu. Chicago: University of Chicago Press.

Taylor, N. (2010) 'Animal Shelter Emotion Management: A case of In Situ Hegemonic Resistance?', Sociology, 44(1): 85-101.

Thoits, P. (1989) 'The Sociology of Emotions', Annual Review of Sociology, 15: 317-342.

Turner, J. (2009), 'The Sociology of Emotions: Basic Theoretical Arguments', Emotion Review, 1: 340-354.

Turner, J. (2010) 'The Stratification of Emotions: Some Preliminary Generalizations', Sociological Inquiry, 80(2): 168-199.

Turner, J. and J. Stets (2005) The Sociology of Emotions. New York: Cambridge University Press. 
Turner, J., Stets, J., Cook, K. and D. Massey (2006) 'Sociological Theories of Human Emotions', Annual Review of Sociology, 32: 25-52.

Urry, J. (2005) 'Beyond the Science of 'Society", Sociological Research Online, $10(2)$

von Scheve, C. and R. von Luede (2005) 'Emotion and Social Structures: Towards an Interdisciplinary Approach', Journal for the Theory of Social Behaviour, 35(3): 303-328.

Wang, Y. and C. Roberts (2006) 'Schadenfreude: A Case Study of Emotion as Situated Discursive Display', Comparative Sociology, 5(1): 45-63.

Wetherall, M. (2013) 'Affect and Discourse-What's the Problem? From Affect as Excess to Affective/Discursive Practice', Subjectivity, 6(4): 349-368.

Weyher, L. (2012) 'Re-reading Sociology via the Emotions: Karl Marx's Theory of Human Nature and Estrangement', Sociological Perspectives, 55(2): 341363.

Williams, S. and G. Bendelow (1996) 'Emotions and 'Sociological Imperialism': A Rejoinder to Craib', Sociology, 30(1): 145-153.

Witz, A. (1992) Professions and Patriarchy. London: Routledge.

Wouters, C. (1992) 'On Status Competition and Emotion Management: The Study of Emotions as a New Field', Theory, Culture \& Society, 9: 229-252.

Wouters, C. (1995) 'Etiquette Books and Emotion Management in the 20th Century: Part Two - the Integration of the Sexes', Journal of Social History, 29(2): 325-339. 